Annales Geophysicae (2003) 21: 603-613 (C) European Geosciences Union 2003

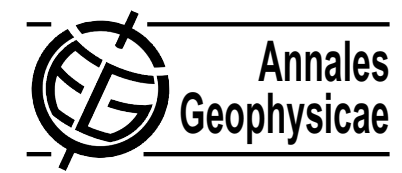

\title{
The estimation of D-region electron densities from riometer data
}

\author{
J. K. Hargreaves ${ }^{1}$ and M. Friedrich ${ }^{2}$ \\ ${ }^{1}$ Department of Communication Systems, University of Lancaster, Lancaster, UK \\ ${ }^{2}$ Department of Communications and Wave Propagation, Technical University of Graz, Graz, Austria
}

Received: 7 March 2002 - Revised: 3 July 2002 - Accepted: 23 August 2002

\begin{abstract}
At high latitude the hard electron precipitation associated with auroral activity is a major source of ionization for the D-region, one consequence being the absorption of radio waves. Direct measurements of the D-region electron density are not readily available, however. This paper investigates the relationship between the electron density at altitudes between 100 and $70 \mathrm{~km}$ and the total radio absorption observed with a riometer, with a view to using the latter to predict the former. Tables are given of the median electron density corresponding to $1 \mathrm{~dB}$ absorption at $27.6 \mathrm{MHz}$ for each hour of the day, and it is shown that at certain heights the estimates will be accurate to within a factor of 1.6 on $50 \%$ of the occasions. A systematic variation with time of day is probably associated with a progressive hardening of the typical electron spectrum during the morning hours. There is also evidence for a seasonal effect possibly due to seasonal variations of the mesosphere.
\end{abstract}

Key words. Ionosphere (auroral ionosphere) - Radio science (ionospheric propagation; instruments and techniques)

\section{Introduction}

In the auroral regions the principal source of D-region ionization is the flux of energetic electrons during auroral activity. There are, of course, contributions from other sources, such as solar electromagnetic emissions (particularly Lyman$\alpha$ and X-rays), and these are enhanced during solar flares. Solar protons cause ionization down to relatively low altitudes during solar proton events, but such events are much less frequent than auroral precipitation. Overall, the electron flux at energies from a few tens of $\mathrm{keV}$ to a few hundred $\mathrm{keV}$ may be assumed to be the dominant source most of the time, contributions from other ionization sources being generally less significant.

Direct observations in the D-region may be made by rocket-borne instruments, and although these techniques are

Correspondence to: J. K. Hargreaves

(J.Hargreaves@lancaster.ac.uk) well established (Mechtly, 1974; Jacobsen and Friedrich, 1979), they are expensive and the data are limited because each flight produces only a single profile. Since the mid 1970s, and more particularly, since the EISCAT system began to operate in the early $1980 \mathrm{~s}$, it has been possible to measure electron densities in the D-region by incoherent scatter radar (Hunsucker, 1974; Ranta et al., 1985; Devlin et al., 1986). Under good conditions it is possible to obtain accurate measurements at $1 \mathrm{~km}$ height resolution and $10 \mathrm{~s}$ time resolution. Radar is considerably less sensitive than the rocketborne probes but it may provide continuous runs of data over several hours. However, the radar data are still limited because incoherent scatter radars are few in number and immobile, and they are also expensive to operate.

Another way of detecting enhancements in the D-region is by measuring the absorption of a radio signal that has passed through the medium. This is the purpose of the riometer technique in which the intensity of the cosmic radio noise at some frequency, usually between 20 and $60 \mathrm{MHz}$, is monitored using a stable receiver at the ground (Hargreaves, 1969). The riometer is relatively cheap and simple to operate. Many of them have been, and still are, in use.

This paper addresses the question of whether riometer data may realistically be used to indicate the electron density at a selected altitude. The depth to which an incoming electron penetrates into the atmosphere depends on its initial energy (Rees, 1963), the more energetic ones depositing their energy at lower altitudes. The resulting electron-density profile, therefore, depends on the original spectrum of the incident particles. Then, if the electron density is $N_{e}(h)$, the absorption of a radio wave of angular frequency $\omega=2 \pi f$ is

$A(d B)=4.6 \times 10^{-5} \int \frac{N_{e}(h) v(h)}{\omega^{2}+v(h)^{2}} d h$,

(Hargreaves, 1969) where $v(\mathrm{~h})$ is the electron-neutral collision frequency. While $v(\mathrm{~h})$ is a property of the atmosphere (i.e. proportional to pressure), $N_{e}(h)$ depends on the incoming electron flux over a band of energies and thus, also on the particle energy. Since the spectrum of the ionizing electrons is not constant, one cannot expect to find a precise rela- 
(a)

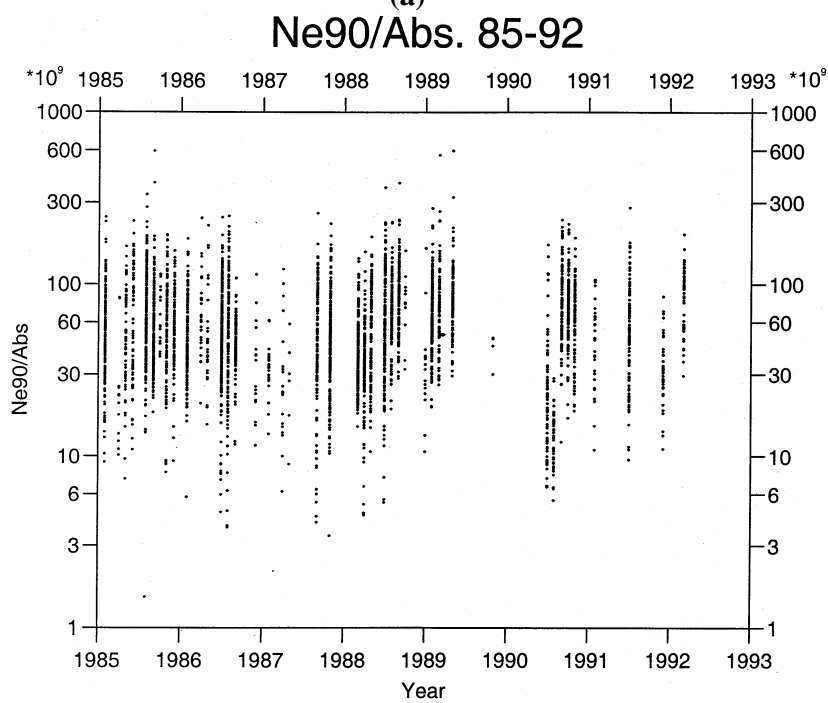

(b)

Data distribution in hour and month, 85-92

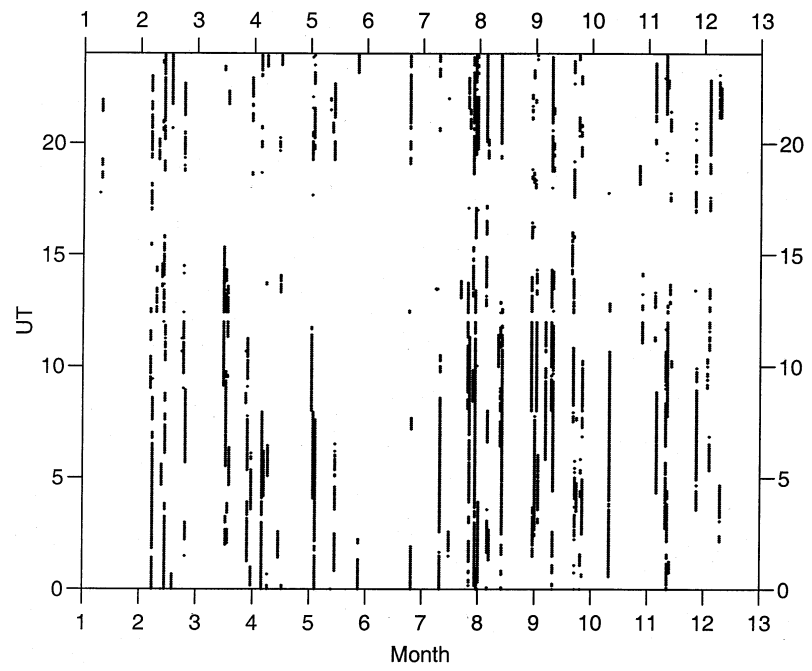

Fig. 1. (a) Value of $90 \mathrm{~km}$ electron density corresponding to $1 \mathrm{~dB}$ absorption for the whole data set between 1985 and 1992 .

(b) Distribution of data points with month and time of day.

tionship between radio absorption and electron density. But neither is the spectrum entirely random. Therefore, we may reasonably ask to what extent, if any, ground-based absorption measurements may be used to indicate D-region electron density, and, if so, what will be the accuracy of these estimates.

\section{The present investigation and data used}

Friedrich and Kirkwood (2000) have published average electron-density profiles corresponding to selected absorption levels. Most of the data came from EISCAT for the (a)

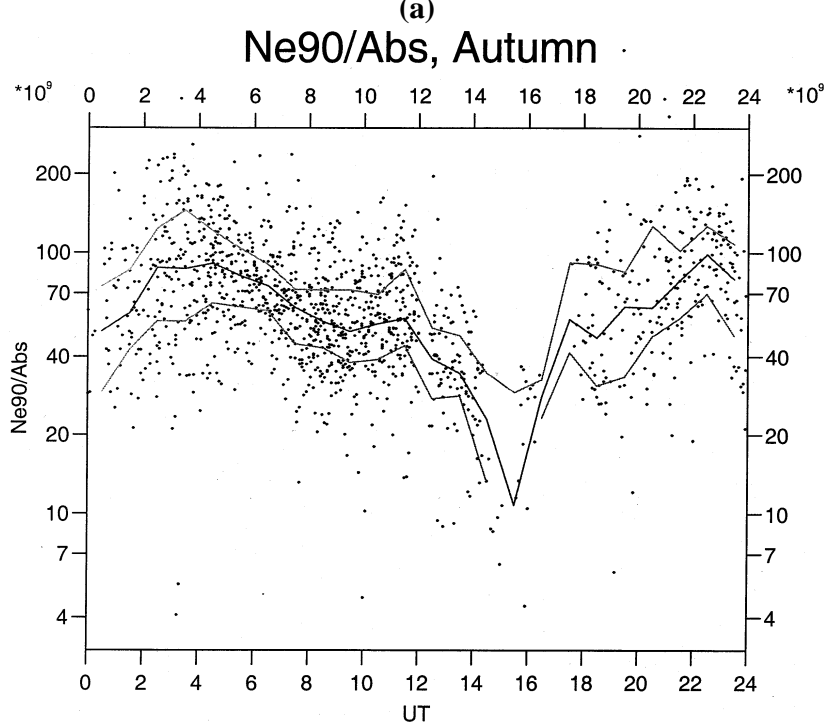

(b)

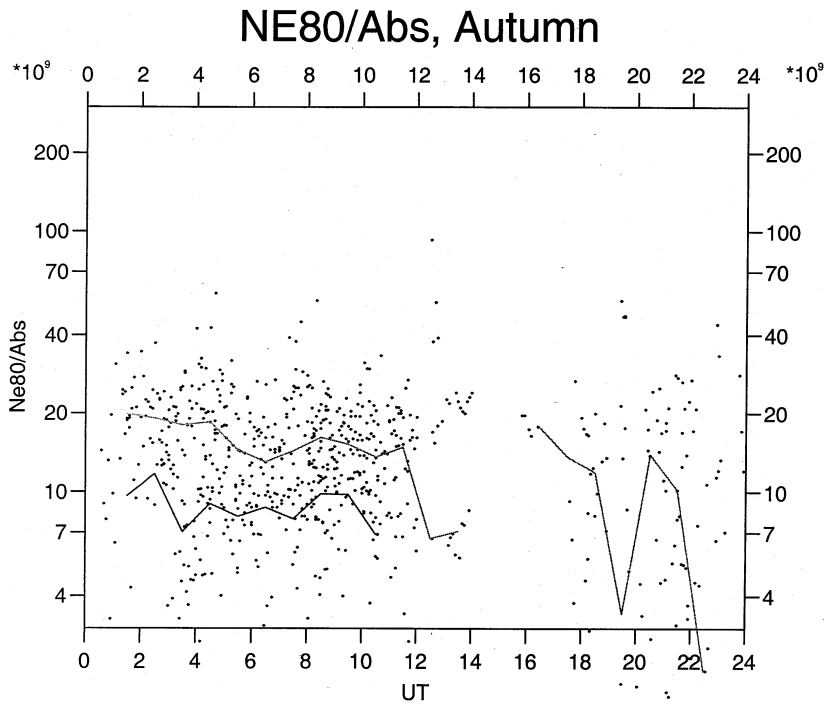

Fig. 2. Values of $N_{e} / A$ against time of day for (a) $90 \mathrm{~km}$ and (b) $80 \mathrm{~km}$.

greater heights and from rockets for the lower ones below about $80 \mathrm{~km}$. The profiles were divided according to whether or not the D-region was illuminated by the Sun. The present study seeks to extend those results in two directions: by specifying the likely accuracy of the estimates, and by looking at the change from night to day in greater detail.

The electron density values are taken from EISCAT UHF common programme runs over the years 1985 to 1992, inclusive. The heights 70 to $100 \mathrm{~km}$ were selected at $5 \mathrm{~km}$ intervals. Each of the electron-density profiles was inspected to eliminate poor data. In cases where the return was too weak for a reliable electron density to be determined, the value zero was substituted. The absorption measurements are taken as averages from four riometers within $10 \mathrm{~km}$ of the radar 
Table 1. Median electron density corresponding to $1 \mathrm{~dB}$ absorption for each height and each hour of the day, using data from all years and months. The $*$ indicates an upper quartile

\begin{tabular}{|c|c|c|c|c|c|c|c|c|}
\hline \multirow[b]{2}{*}{ UT } & \multirow{2}{*}{$\begin{array}{r}\text { No. } \\
\text { of } \\
\text { Values }\end{array}$} & \multicolumn{7}{|c|}{ Height } \\
\hline & & $100 \mathrm{~km}$ & $95 \mathrm{~km}$ & $90 \mathrm{~km}$ & $85 \mathrm{~km}$ & $80 \mathrm{~km}$ & $75 \mathrm{~km}$ & $70 \mathrm{~km}$ \\
\hline 0.5 & 188 & $.231 \mathrm{E} 12$ & $.129 \mathrm{E} 12$ & $.414 \mathrm{E} 11$ & $.745 \mathrm{E} 10$ & $.219 \mathrm{E} 10 *$ & $.000 \mathrm{E} 00^{*}$ & $.000 \mathrm{E} 00^{*}$ \\
\hline 1.5 & 195 & $.152 \mathrm{E} 12$ & $.112 \mathrm{E} 12$ & $.481 \mathrm{E} 11$ & $.100 \mathrm{E} 11$ & $.490 \mathrm{E} 10 *$ & $.000 \mathrm{E} 00^{*}$ & $.000 \mathrm{E} 00^{*}$ \\
\hline 2.5 & 237 & $.179 \mathrm{E} 12$ & $.129 \mathrm{E} 12$ & $.617 \mathrm{E} 11$ & $.148 \mathrm{E} 11$ & $.960 \mathrm{E} 10 *$ & $.000 \mathrm{E} 00 *$ & $.000 \mathrm{E} 00^{*}$ \\
\hline 3.5 & 226 & $.163 \mathrm{E} 12$ & $.120 \mathrm{E} 12$ & $.551 \mathrm{E} 11$ & $.161 \mathrm{E} 11$ & $.326 \mathrm{E} 10$ & $.000 \mathrm{E} 00 *$ & $.000 \mathrm{E} 00^{*}$ \\
\hline 4.5 & 254 & $.142 \mathrm{E} 12$ & $.128 \mathrm{E} 12$ & $.805 \mathrm{E} 11$ & $.273 \mathrm{E} 11$ & $.589 \mathrm{E} 10$ & $.243 \mathrm{E} 10^{*}$ & $.000 \mathrm{E} 00^{*}$ \\
\hline 5.5 & 271 & $.980 \mathrm{E} 11$ & $.895 \mathrm{E} 11$ & $.714 \mathrm{E} 11$ & $.255 \mathrm{E} 11$ & $.640 \mathrm{E} 10$ & $.437 \mathrm{E} 10^{*}$ & $.000 \mathrm{E} 00^{*}$ \\
\hline 6.5 & 258 & $.965 \mathrm{E} 11$ & $.901 \mathrm{E} 11$ & $.688 \mathrm{E} 11$ & $.266 \mathrm{E} 11$ & $.734 \mathrm{E} 10$ & $.463 \mathrm{E} 10^{*}$ & $.000 \mathrm{E} 00^{*}$ \\
\hline 7.5 & 252 & $.852 \mathrm{E} 11$ & $.771 \mathrm{E} 11$ & $.625 \mathrm{E} 11$ & $.236 \mathrm{E} 11$ & $.702 \mathrm{E} 10$ & $.373 \mathrm{E} 10^{*}$ & $.000 \mathrm{E} 00^{*}$ \\
\hline 8.5 & 260 & $.643 \mathrm{E} 11$ & $.636 \mathrm{E} 11$ & $.539 \mathrm{E} 11$ & $.251 \mathrm{E} 11$ & $.855 \mathrm{E} 10$ & $.447 \mathrm{E} 10^{*}$ & $.000 \mathrm{E} 00^{*}$ \\
\hline 9.5 & 243 & $.747 \mathrm{E} 11$ & $.657 \mathrm{E} 11$ & $.518 \mathrm{E} 11$ & $.235 \mathrm{E} 11$ & $.774 \mathrm{E} 10$ & $.527 \mathrm{E} 10^{*}$ & $.000 \mathrm{E} 00^{*}$ \\
\hline 10.5 & 236 & $.720 \mathrm{E} 11$ & $.625 \mathrm{E} 11$ & $.500 \mathrm{E} 11$ & $.202 \mathrm{E} 11$ & $.572 \mathrm{E} 10$ & $.495 \mathrm{E} 10^{*}$ & $.000 \mathrm{E} 00^{*}$ \\
\hline 11.5 & 198 & $.768 \mathrm{E} 11$ & $.660 \mathrm{E} 11$ & $.512 \mathrm{E} 11$ & $.191 \mathrm{E} 11$ & $.124 \mathrm{E} 11 *$ & $.000 \mathrm{E} 00 *$ & $.000 \mathrm{E} 00 *$ \\
\hline 12.5 & 114 & $.624 \mathrm{E} 11$ & $.572 \mathrm{E} 11$ & $.356 \mathrm{E} 11$ & $.132 \mathrm{E} 11$ & $.676 \mathrm{E} 10 *$ & $.000 \mathrm{E} 00^{*}$ & $.000 \mathrm{E} 00^{*}$ \\
\hline 13.5 & 156 & $.581 \mathrm{E} 11$ & $.449 \mathrm{E} 11$ & $.328 \mathrm{E} 11$ & $.764 \mathrm{E} 10$ & $.000 \mathrm{E} 00 *$ & $.000 \mathrm{E} 00^{*}$ & $.000 \mathrm{E} 00^{*}$ \\
\hline 14.5 & 90 & $.571 \mathrm{E} 11$ & $.434 \mathrm{E} 11$ & $.305 \mathrm{E} 11$ & $.903 \mathrm{E} 10$ & $.485 \mathrm{E} 10 *$ & $.000 \mathrm{E} 00 *$ & $.000 \mathrm{E} 00^{*}$ \\
\hline 15.5 & 37 & $.407 \mathrm{E} 11$ & $.293 \mathrm{E} 11$ & $.222 \mathrm{E} 11$ & $.603 \mathrm{E} 10$ & $.000 \mathrm{E} 00 *$ & $.000 \mathrm{E} 00 *$ & $.000 \mathrm{E} 00^{*}$ \\
\hline 16.5 & 27 & $.551 \mathrm{E} 11$ & $.405 \mathrm{E} 11$ & $.280 \mathrm{E} 11$ & $.188 \mathrm{E} 11 *$ & $.000 \mathrm{E} 00 *$ & $.000 \mathrm{E} 00^{*}$ & $.000 \mathrm{E} 00^{*}$ \\
\hline 17.5 & 45 & $.181 \mathrm{E} 12$ & $.789 \mathrm{E} 11$ & $.386 \mathrm{E} 11$ & $.137 \mathrm{E} 11$ & $.936 \mathrm{E} 10 *$ & $.000 \mathrm{E} 00^{*}$ & $.000 \mathrm{E} 00^{*}$ \\
\hline 18.5 & 65 & $.190 \mathrm{E} 12$ & $.889 \mathrm{E} 11$ & $.455 \mathrm{E} 11$ & $.172 \mathrm{E} 11$ & $.989 \mathrm{E} 10 *$ & $.000 \mathrm{E} 00^{*}$ & $.000 \mathrm{E} 00^{*}$ \\
\hline 19.5 & 133 & $.144 \mathrm{E} 12$ & $.841 \mathrm{E} 11$ & $.355 \mathrm{E} 11$ & $.165 \mathrm{E} 11 *$ & $.000 \mathrm{E} 00 *$ & $.000 \mathrm{E} 00^{*}$ & $.000 \mathrm{E} 00 *$ \\
\hline 20.5 & 172 & $.117 \mathrm{E} 12$ & $.648 \mathrm{E} 11$ & $.340 \mathrm{E} 11$ & $.557 \mathrm{E} 10$ & $.290 \mathrm{E} 10 *$ & $.000 \mathrm{E} 00^{*}$ & $.000 \mathrm{E} 00^{*}$ \\
\hline 21.5 & 236 & $.176 \mathrm{E} 12$ & $.116 \mathrm{E} 12$ & $.516 \mathrm{E} 11$ & $.123 \mathrm{E} 11$ & $.536 \mathrm{E} 10 *$ & $.000 \mathrm{E} 00^{*}$ & $.000 \mathrm{E} 00 *$ \\
\hline 22.5 & 218 & $.191 \mathrm{E} 12$ & $.142 \mathrm{E} 12$ & $.690 \mathrm{E} 11$ & $.134 \mathrm{E} 11$ & $.395 \mathrm{E} 10 *$ & $.000 \mathrm{E} 00^{*}$ & $.000 \mathrm{E} 00 *$ \\
\hline 23.5 & 186 & $.248 \mathrm{E} 12$ & $.157 \mathrm{E} 12$ & $.518 \mathrm{E} 11$ & $.863 \mathrm{E} 10$ & $.000 \mathrm{E} 00 *$ & $.000 \mathrm{E} 00^{*}$ & $.000 \mathrm{E} 00^{*}$ \\
\hline
\end{tabular}

site at Ramfjordmoen, Norway $\left(69.6^{\circ} \mathrm{N}, 19.2^{\circ} \mathrm{E}, L=6.2\right)$, specifically two each at Ramfjordmoen and at Lavangsdalen. The absorption values are converted to $27.6 \mathrm{MHz}, \mathrm{X}$-mode and vertical incidence (Friedrich et al., 2002). Both data sets are at a 5-min interval. Since the riometer data are relatively less accurate at small values, and to reduce the effect of solar contributions to the absorption (which could amount to a few tenths of a dB at noon), only values of at least $0.5 \mathrm{~dB}$ are used in the following analysis.

\section{Data analysis}

Since the absorption at a given height is proportional to the electron density (Eq. 1), we work with the ratio $N_{e}(h) / A$, where $N_{e}(h)$ is the electron density in $\mathrm{m}^{-3}$ at height $h$ and $A$ is the total absorption at $27.6 \mathrm{MHz}$ in $\mathrm{dB}$. Figure 1 a shows the values of $N_{e}(90) / A$ over the whole data set against the year. Its value spreads by about a factor of 10 , but there is no indication of a systematic variation from year to year. We shall, therefore, take all the years together. Figure 1b shows the distribution of data points with month and time of day. This distribution is less even than we might wish. The gap in the afternoon corresponds with the low occurrence of auroral absorption at that time of day, which is well known (Harg- reaves and Cowley, 1967), but the gaps during the summer period, and during the winter, from Christmas to the end of January, are plainly observational and due to the schedules of radar operations.

As an example of the results, Fig. 2 shows the values of $N_{e} / A$ for 90 and $80 \mathrm{~km}$ for the autumn period (months 8.2511.25 ) against time of day, with medians and quartiles superimposed. At $90 \mathrm{~km}$ there is a marked variation with time of day, particularly during the morning hours. That variation is not apparent at $80 \mathrm{~km}$. In that case, however, medians were obtained only for the hours 01:00 to 11:00 UT. At other times only the upper quartiles are shown. The lower quartiles are lost in the zeros of the data set, and are not plotted; they fall below the limit of measurement.

Table 1 summarizes the median values of electron density corresponding to $1 \mathrm{~dB}$ absorption for each hour of the UT day. When no median was obtained, the upper quartile is marked with an asterisk. This table uses the values from all months. The relative lack of data in summer and winter makes it more difficult to look for seasonal variations, but we will return to this point in a later section.

When the value zero appears in Table 1, it means that even the upper quartile was below the threshold of measurement. We can estimate that threshold from the distribution of measured electron density (Fig. 3). Since each value is 

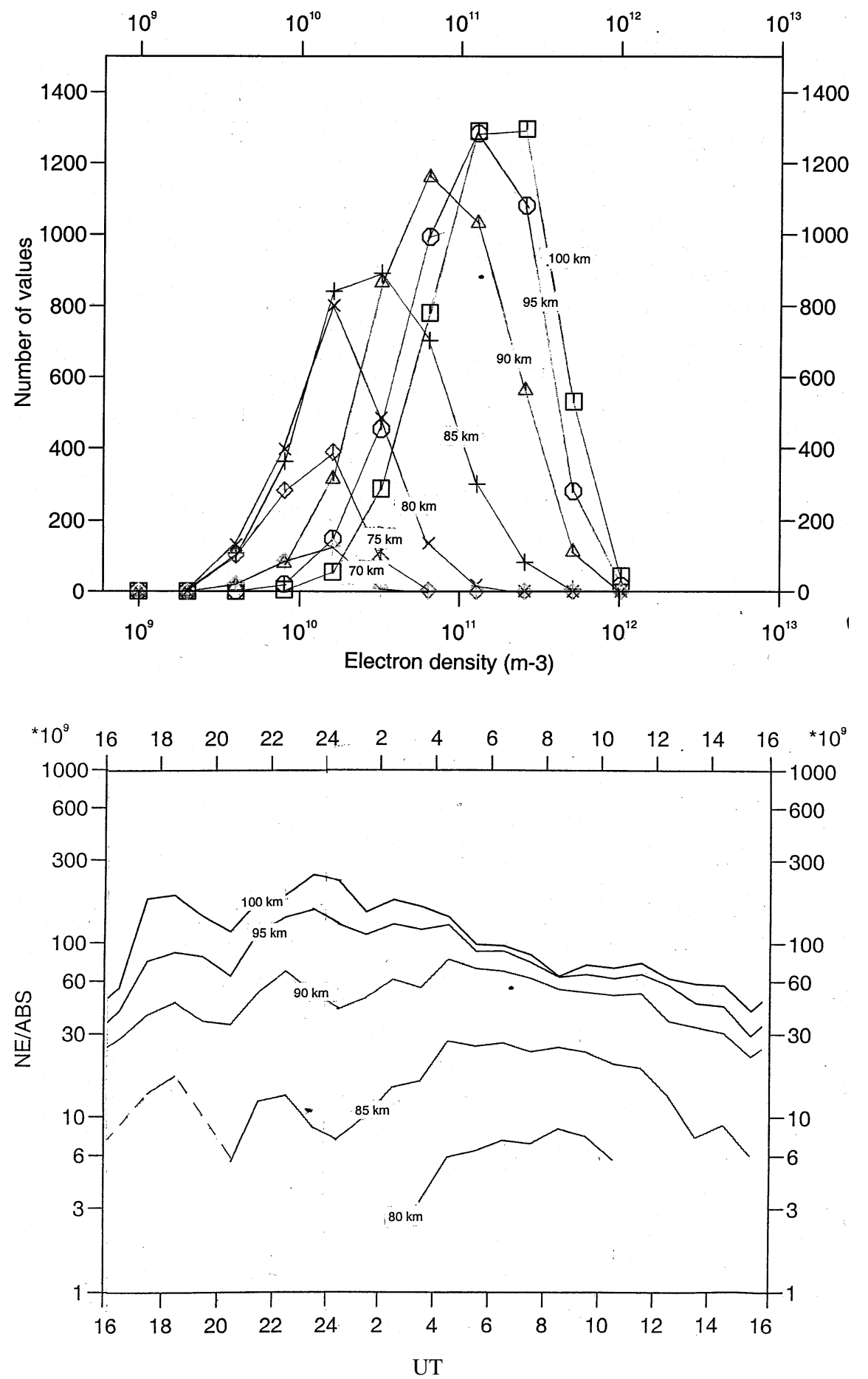

Fig. 3. Histograms of electron density from $100 \mathrm{~km}$ to $70 \mathrm{~km}$.
Fig. 4. Medians for whole data set, 1985-1992. Variation of median electron density (for $1 \mathrm{~dB}$ absorption) with time of day. At EISCAT local magnetic midnight is about 21:30 UT. The data show a daily cycle starting about six hours before magnetic midnight. taken from a complete profile covering 70 to $100 \mathrm{~km}$, there should be the same number of readings for each altitude. But whereas we see similar distributions, though with different medians, for 100, 95 and $90 \mathrm{~km}$, fewer values appear at and below $80 \mathrm{~km}$. Clearly, the numbers fall off significantly below about $10^{10} \mathrm{~m}^{-3}$, the missing values having been designated as zero during the initial editing of the data. This may be checked by counting the number of zeros in each height group (Table 2). Down to $90 \mathrm{~km}$ fewer than $5 \%$ of the readings fell below threshold, whereas at $70 \mathrm{~km}$ only $6 \%$ were above it. It must be remembered that this result is for conditions where the $27.6 \mathrm{MHz}$ absorption was at least $0.5 \mathrm{~dB}$. A different absorption limit would produce a different distribution in Table 2, though the absolute threshold of approximately $10^{10} \mathrm{~m}^{-3}$ would presumably be the same. 
Table 2. Numbers of electron-density values and of zeros in the data set

\begin{tabular}{lrrrrrrr}
\hline Height & $100 \mathrm{~km}$ & $95 \mathrm{~km}$ & $90 \mathrm{~km}$ & $85 \mathrm{~km}$ & $80 \mathrm{~km}$ & $75 \mathrm{~km}$ & $70 \mathrm{~km}$ \\
\hline $\begin{array}{l}\text { Number of electron } \\
\text { density values }\end{array}$ & 4295 & 4282 & 4149 & 3300 & 1968 & 870 & 244 \\
Number of zeros & 1 & 14 & 147 & 996 & 2328 & 3426 & 4152 \\
$\%$ of zeros & 0.02 & 0.33 & 3.4 & 23 & 54 & 79 & 94 \\
\hline
\end{tabular}

Table 3. Spread of values in terms of median and quartiles

\begin{tabular}{lccccccc}
\hline Height & $100 \mathrm{~km}$ & $95 \mathrm{~km}$ & $90 \mathrm{~km}$ & $85 \mathrm{~km}$ & $80 \mathrm{~km}$ & $75 \mathrm{~km}$ & $70 \mathrm{~km}$ \\
\cline { 1 - 5 } $\begin{array}{l}\text { Median } \\
\text { Lower quartile }\end{array}$ & 1.59 & 1.63 & 1.60 & 2.44 & - & - & - \\
$\begin{array}{l}\text { Upper quartile } \\
\text { Median }\end{array}$ & 1.52 & 1.49 & 1.50 & 1.71 & 2.12 & - & - \\
$\begin{array}{l}\text { Upper quartile } \\
\text { Lower quartile }\end{array}$ & 2.42 & 2.43 & 2.40 & 4.17 & - & - & - \\
\hline
\end{tabular}

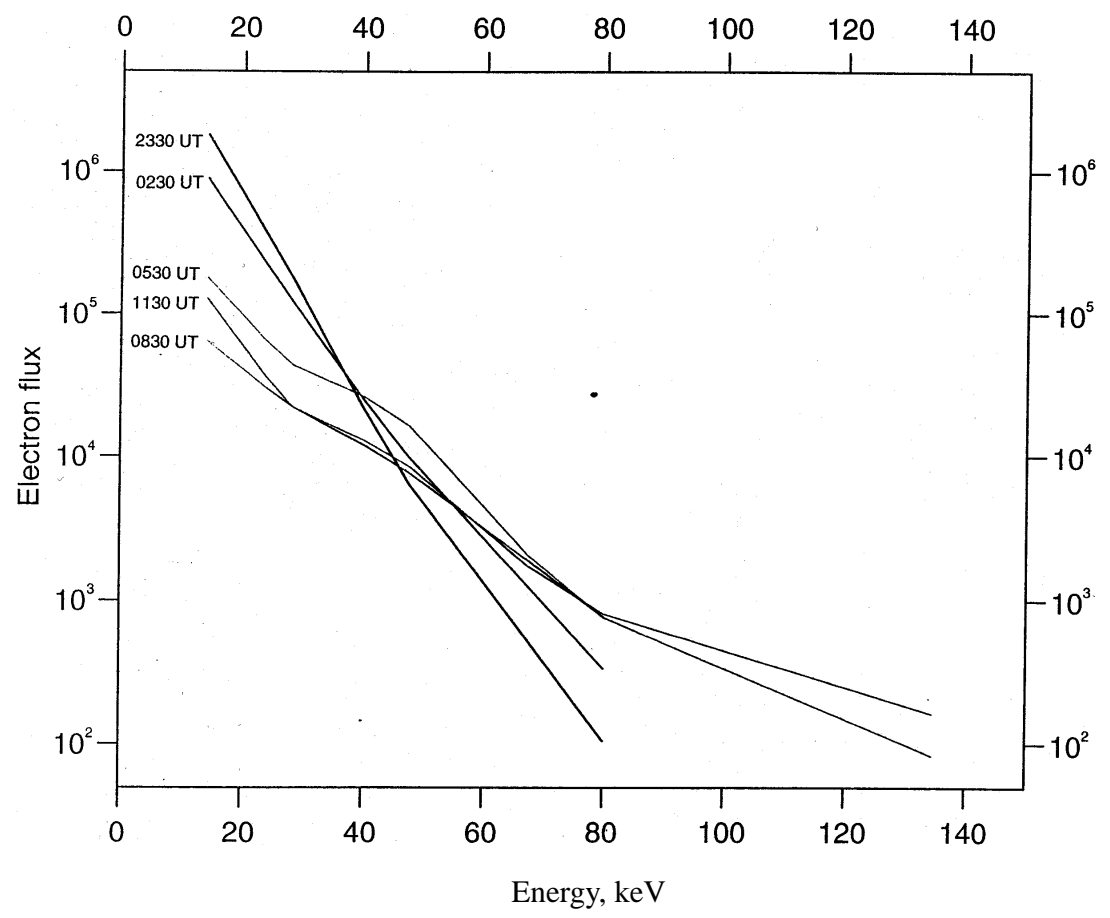

Fig. 5. Spectra deduced from the median electron-density profiles from night to morning.

\section{Prediction model for the whole year}

The overall results are summarized in Fig. 4, which gives the hourly medians for each height. Note that at $75 \mathrm{~km}$ and below the medians were all below the radar threshold. At $80 \mathrm{~km}$ the values were above the threshold only between 03:00 and 11:00 UT. Systematic trends are apparant. At 100 and $95 \mathrm{~km}$ the ratio $N_{e} / A$ decreases steadily from the midnight sector into the daytime, whereas the lower heights show an increase followed by a decrease during the morning hours. The dips at 20:00 UT are probably statistical.

In order to serve as a prediction model, the information in Fig. 4 needs to be supplimented by a knowledge of the spread of the values contributing to each median. Table 3 shows the relationship between quartiles and median at the various heights. At $90 \mathrm{~km}$ and above, the ratios (upper quar- 
(a)

\section{Ne90/Abs against solar zenith angle}

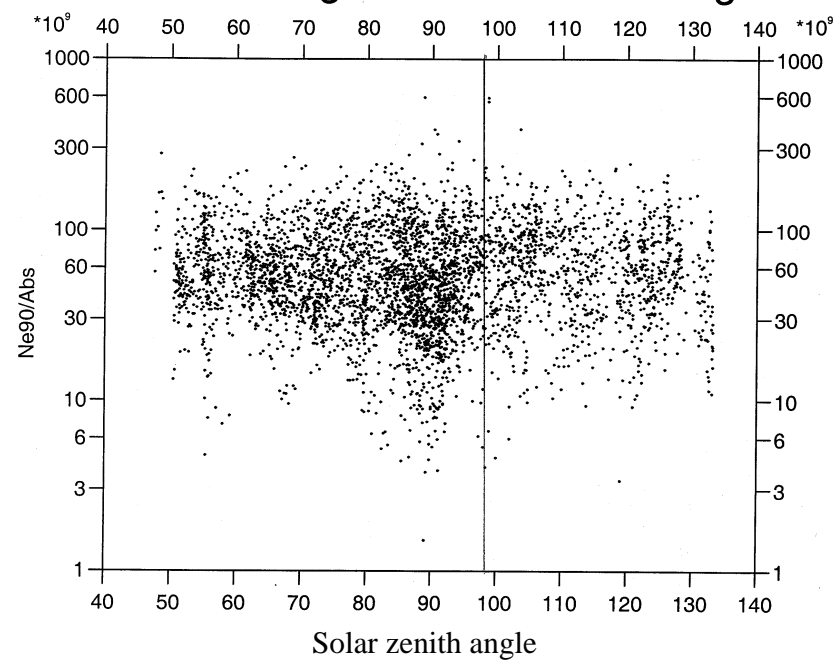

(b)

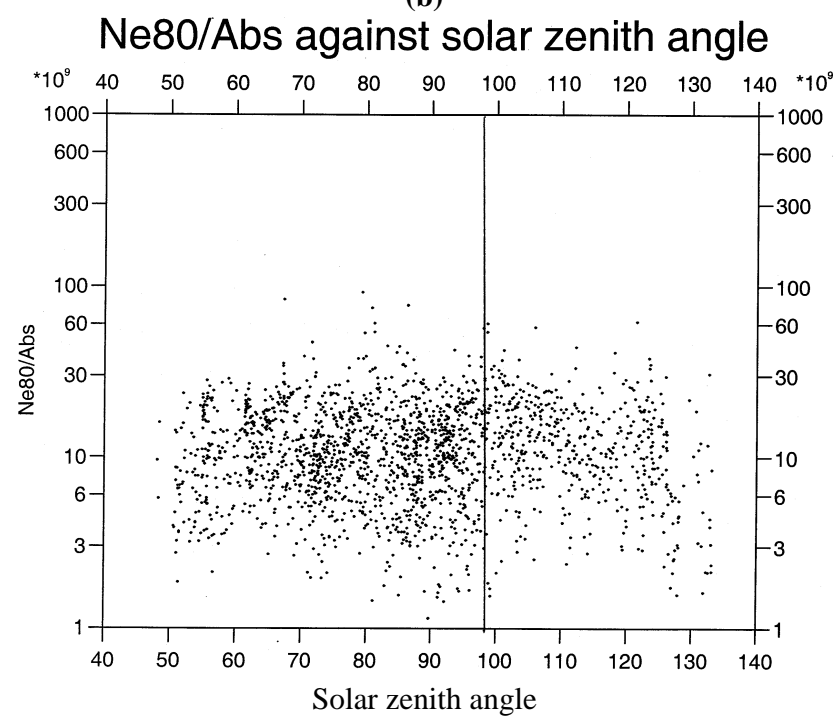

Fig. 6. $N_{e} / A$ against the solar zenith angle.

tile)/median and median/(lower quartile) are both about 1.5 or 1.6. This means that there is a $50 \%$ chance that a single estimate will be within 1.6 of the true value. The spread is somewhat worse at the lower heights.

\section{Significance of the diurnal variation}

The electron-density profile may be inverted to give an indication of the spectrum of incoming particles that produced it (Hargreaves and Devlin, 1990). Some assumptions have to be made about the atmospheric composition and about the effective recombination coefficient as a function of altitude. Although the absolute values may be questioned, this approach is useful for interpreting changes of profile in terms of a changing spectrum. Treating in this way the median profiles for 23:00-24:00 UT and each $3 \mathrm{~h}$ to 11:00-12:00 UT (Fig. 5) shows a hardening of the typical spectrum with time. The earliest spectrum is almost exponential with characteristic energy $6.5 \mathrm{keV}$, a value consistent with other determinations for that time of day (Devlin et al., 1986). Later in the morning, the characteristic energy is considerably greater, about $16 \mathrm{keV}$. This hardening is also consistent with previous observations of individual events (Hargreaves and Devlin, 1990).

\section{The question of photodetachment}

In polar-cap absorption events (PCA), which result from the incidence of solar protons, the level of absorption changes drastically between day and night, according to whether or not the ionosphere is sunlit (Bailey, 1957). Such a transition is expected because the effective electron recombination in the lower ionosphere increases drastically in the absence of daylight, due to attachment of electrons to neutrals and the enhanced formation of cluster ions. PCA occurs lower in the atmosphere than auroral absorption (AA), and attempts to identify the same effect in AA (most notably the analysis by Armstrong et al., 1977) have failed to find one.

In Fig. 6 we show the quantity $N_{e} / A$ against the solar zenith angle $(\chi)$, for two altitudes. It will be noted that there is no sharp change between $\chi=90$ and $100^{\circ}$, as would be the case in PCA. We note, further, that the absorption profiles (Fig. 7) corresponding to the spectra of Fig. 5 peak between 90 and $95 \mathrm{~km}$; the contribution at and below $75 \mathrm{~km}$ is likely to be small. Incoherent-scatter radar studies of PCA, however, show that most of the day/night variation of electron density in those events is strongly height dependent, and is rather small above $75 \mathrm{~km}$ (Reagan and Watt, 1976; Collis and Rietveld, 1990; Hargreaves et al., 1993). For large ionisation rates, such as those considered in the present context (absorption larger than $0.5 \mathrm{~dB}$ ), the cluster ledge is most likely to be always below $80 \mathrm{~km}$. We conclude that the diurnal variation shown in Fig. 4 and Table 1 is a consequence of a changing electron spectrum, not of solar illumination.

\section{Seasonal variation}

The scheme described above takes into account daily but not seasonal variations. To include both variables requires the data to be sorted into 288 boxes to cover each hour of each month, and since the distribution is uneven some of these boxes will contain too few data points for a significant result. Therefore, median values of the ratio $N_{e} / A$ were derived only for those boxes containing at least 30 points. These values are given in Tables A1-5, covering heights 100 to $80 \mathrm{~km}$, in the Appendix. As before, zero means that the median value was below the threshold of observation. Based on the general statistics (Sect. 3), it is estimated that about half the medians in the tables will not be within $10 \%$ of the true value. In comparing values, therefore, differences less 


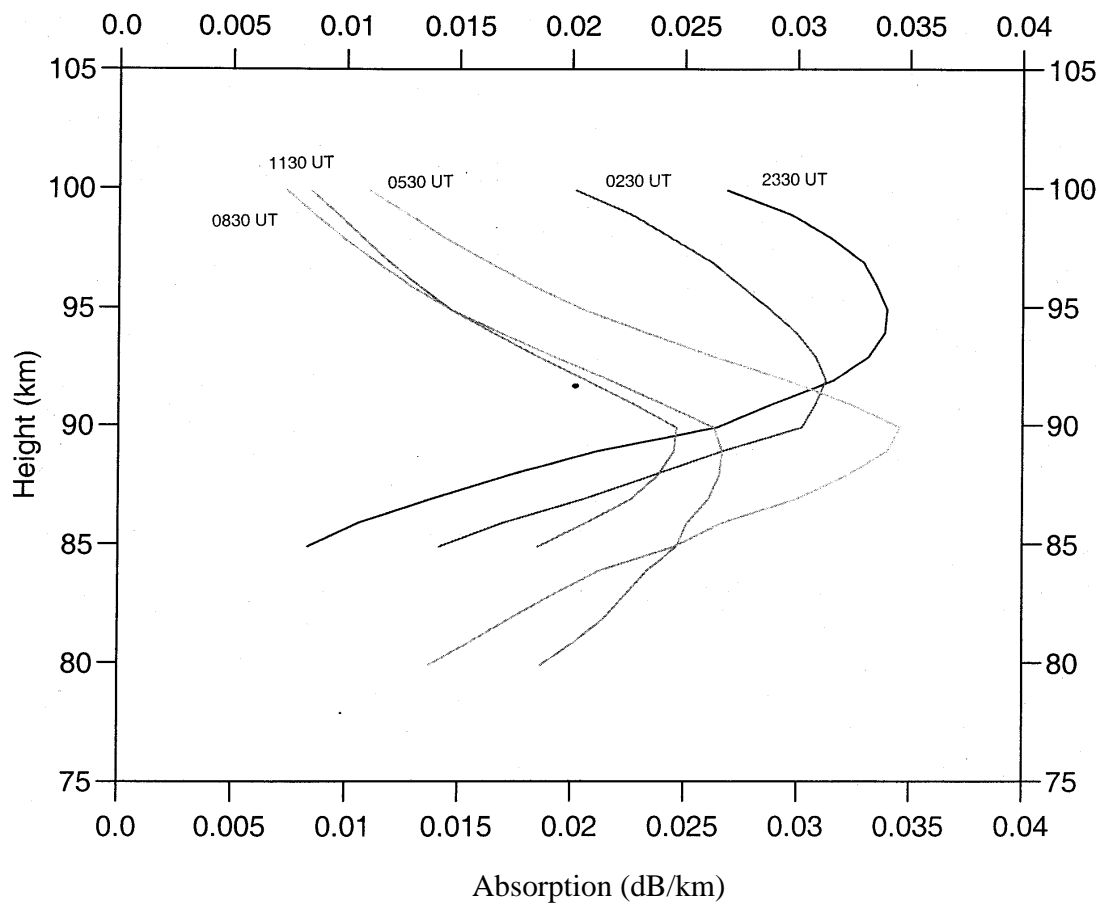

Fig. 7. Partial absorption profiles corresponding to the median electrondensity profiles in the night-to-morning sector. than $10 \%$ should not be considered significant. Differences of more than $50 \%$ are likely to be significant.

The best coverage across all months is between 04:00 and 07:00 UT. We can also compare the variations during the day by taking together November to March (as winter) and July to August (as summer), though both these groups lack data from 14:00 to 20:00 UT. The reader may like to draw his or her own conclusions, but the authors offer the following comments:

1. At 100 and $95 \mathrm{~km}$, the value of electron density corresponding to $1 \mathrm{~dB}$ absorption is relatively high in summer around 00:00 UT, but relatively low for several hours before that.

2. At $90 \mathrm{~km}$, the summer maximum at 00:00 UT has vanished, though values are still low before that time.

3. At $85 \mathrm{~km}$, the low values before 00:00 UT are now below the threshold. There is now also a dip during the early morning (05:00 to 07:00 UT).

4. At $80 \mathrm{~km}$, all summer values are low relative to those at other times of the year.

For a given spectrum of incoming energetic electrons, the ionization rate and the effective recombination coefficient, and, therefore, the ionization profile, are all influenced by the vertical profiles of density and pressure in the mesosphere. Further, the resulting radio absorption depends on the electron-neutral collision frequency, which is also pressure dependent. Direct measurements of atmospheric density at high latitude show a reduction in summer at 100 and $95 \mathrm{~km}$, and a summer increase at 85 and $80 \mathrm{~km}$. The seasonal variations indicated by Tables A1-5 may well be a consequence of mesospheric changes, but due to the inherent limitations of the data they should be regarded as indications rather than definitive determinations.

\section{Conclusions and discussion}

1. An analysis of incoherent-scatter and riometer data over a period of 8 years, including more than 4000 individual measurements, shows that an observation of auroral radio absorption may be interpreted to estimate the approximate electron density at heights between 100 and $80 \mathrm{~km}$. The results presented apply only if the absorption is at least $0.5 \mathrm{~dB}$. The results are given in terms of the medians, and upper and lower quartiles of the electron density, corresponding to $1 \mathrm{~dB}$ absorption measured with a $27.6 \mathrm{MHz}$ riometer pointed vertically.

2. The uncertainty of the procedure is such that at the greater heights $(100,95$ and $90 \mathrm{~km})$ the estimate will be accurate to within a factor of 1.6 on $50 \%$ of the occasions. At lower heights the error appears to be rather worse.

3. The sensitivity of the EISCAT UHF radar when using 5min averaging is found to be $10^{10} \mathrm{~m}^{-3}$, or a little below, in the D-region. Due to this limit no median values of the electron density corresponding to $1 \mathrm{~dB}$ absorption could be determined at or below $75 \mathrm{~km}$, and the $80-\mathrm{km}$ values are restricted to one period of the day. The upper 
quartile could be specified at 80 and $75 \mathrm{~km}$, but not at $70 \mathrm{~km}$.

4. Since the typical spectrum of incoming energetic electrons varies with the time of day, the estimates of electron density show a diurnal variation. There is no evidence that solar illumination has any effect at $80 \mathrm{~km}$ or above.

5. Dividing the data according to both time-of-day and season suggests that a seasonal effect is also present, but due to data limitations the actual values should be treated with caution.

The absorption values used in this investigation are those actually measured by a simple riometer system using a vertical 5-element Yagi antenna. It is estimated that such an antenna records absorption about $20 \%$ greater than would be measured by an ideal system having a zenithal pencil beam. This factor should be taken into account where appropriate.

Acknowledgements. We thank P. Stauning for providing the riometer data and M. Harrich for the original data processing. EISCAT is supported by Finland (SA), France (CNRS), Germany (MPG), Japan (NIPR), Norway (NFR), Sweden (NFR) and the UK (PPARC).

Topical Editor M. Lester thanks C. Hall and another referee for their help in evaluating this paper.

\section{References}

Armstrong, R. J., Berkey, F. T., and Melbye, T.: The day to night absorption ratio in auroral zone riometer measurements, Planet. Space Sci. 25, 1193-1198, 1977.

Bailey, D. K.: Disturbances in the lower ionosphere observed at VHF following the solar flare of 23 February 1956 with particular reference to auroral-zone absorption, J. Geophys. Res., 62, 431, 1957.

Collis, P. N. and Rietveld, M. T.: Mesospheric observations with the EISCAT UHF radar during polar cap absorption events: 1 . Electron densities and negative ions, Ann. Geophysicae, 8, 809, 1990.

Devlin, T., Hargreaves, J. K., and Collis, P. N.: EISCAT observations of the ionospheric $\mathrm{D}$ region during auroral radio absorption events, J. Atmos. Terr. Phys., 48, 795, 1986.

Friedrich, M. and Kirkwood, S.: The D-region background at high latitudes, Adv. Space Res., 25, 15, 2000.

Friedrich, M., Harrich, M., Torkar, K. M., and Stauning, P.: Quantitative measurements with wide-beam riometers, J. Atmos. SolarTerr. Phys., 64, 359, 2002.

Hargreaves, J. K. and Cowley, F. C.: Studies of auroral radio absorption events at three magnetic latitudes I. Occurrence and statistical properties of the events, Planet. Space Sci., 15, 1571, 1967.

Hargreaves, J. K.: Auroral absorption of HF radio waves in the ionosphere - a review of results from the first decade of riometery, Proc. IEEE, 57, 1348, 1969.

Hargreaves, J. K. and Devlin, T.: Morning sector electron precipitation events observed by incoherent scatter radar, J. Atmos. Terr. Phys., 52, 193, 1990.

Hargreaves, J. K., Shirochkov, A. V., and Farmer, A. D.: The polar cap absorption event of 19-21 March 1990: recombination coefficients, the twilight transition and the midday recovery, J. Atmos. Terr. Phys., 55, 857, 1993.

Hunsucker, R. D.: Simultaneous riometer and incoherent scatter radar observations of the auroral D-region, Radio Science, 9, 335, 1974.

Jacobsen, T. A. and Friedrich, M.: Electron density measurements in the lower D-region, J. Atmos. Terr. Phys., 41, 1195, 1979.

Mechtly, E. A.: Accuracy of rocket measurements of lower ionosphere electron density concentrations, Radio Science, 9, 373, 1974.

Ranta, A., Ranta, H., Turunen, T., Silen, J., and Stauning, P.: High resolution observations of D-region by EISCAT and their comparison to riometer measurements, Planet. Space Sci., 33, 583, 1985.

Reagan, J. B. and Watt, T. M.: Simultaneous satellite and radar studies of the D-region ionosphere during the intense solar particle events of August 1972, J. Geophys. Res., 81, 4579, 1976.

Rees, M. H.: Auroral ionization and excitation by incident energetic electrons, Planet. Space Sci., 11, 1209, 1963.

\section{Appendix}

The following tables give the data for heights of 100 to $80 \mathrm{~km}$ divided by both time of day and season. The values are median electron densities corresponding to $1 \mathrm{~dB}$ absorption at $27.6 \mathrm{MHz}$, and are only given for those boxes having at least 30 data points. Each box is designated according to the central time and month concerned; e.g. "time 5.5, month 6.5" means 05:00 to 06:00 UT in the month of July. 
J. K. Hargreaves and M. Friedrich: The estimation of D-region electron densities from riometer data

Table A1. Median Electron density at $100 \mathrm{~km}$ for $1 \mathrm{~dB}$ absorption

\begin{tabular}{|c|c|c|c|c|c|c|c|c|c|c|c|c|}
\hline Month & 0.5 & 1.5 & 2.5 & 3.5 & 4.5 & 5.5 & 6.5 & 7.5 & 8.5 & 9.5 & 10.5 & 11.5 \\
\hline \multicolumn{13}{|l|}{ Hour (UT) } \\
\hline 0.5 & & 180 & & & & & 341 & & & & & \\
\hline 1.5 & & & & & & & 189 & 144 & & & & \\
\hline 2.5 & & 182 & & & & & & 140 & & & & \\
\hline 3.5 & & & & & & & & 78.6 & 178 & & & \\
\hline 4.5 & & & & & 155 & & 143 & & 142 & & 166 & \\
\hline 5.5 & & & 128 & 66.5 & 88.7 & & 103 & & 109 & & 128 & \\
\hline 6.5 & & 58.9 & 104 & & & & 118 & & 103 & & 115 & \\
\hline 7.5 & & & & & & & 111 & 62.5 & 76.3 & & 81.2 & \\
\hline 8.5 & & & & & & & 101 & 46.6 & 75.3 & & 52.0 & \\
\hline 9.5 & & & 54.6 & & & & 97.8 & & 91.4 & & & \\
\hline 10.5 & & & & & & & 114 & 76.6 & 70.5 & & & \\
\hline 11.5 & & & & & & & & 111 & 76.6 & & & \\
\hline \multicolumn{13}{|l|}{12.5} \\
\hline 13.5 & & & & & & & 95.7 & & 56.9 & & & \\
\hline \multicolumn{13}{|l|}{14.5} \\
\hline \multicolumn{13}{|l|}{15.5} \\
\hline \multicolumn{13}{|l|}{16.5} \\
\hline \multicolumn{13}{|l|}{17.5} \\
\hline \multicolumn{13}{|l|}{18.5} \\
\hline \multicolumn{13}{|l|}{19.5} \\
\hline 20.5 & & 287 & & & & & 64.0 & & & & & \\
\hline 21.5 & & 200 & & & & & 84.6 & & & & & 102 \\
\hline 22.5 & & 208 & & & & & 103 & & & & 244 & \\
\hline 23.5 & & & & & & & 280 & & & & & \\
\hline
\end{tabular}

Table A2. Median Electron density at $95 \mathrm{~km}$ for $1 \mathrm{~dB}$ absorption

\begin{tabular}{|c|c|c|c|c|c|c|c|c|c|c|c|c|}
\hline Month & 0.5 & 1.5 & 2.5 & 3.5 & 4.5 & 5.5 & 6.5 & 7.5 & 8.5 & 9.5 & 10.5 & 11.5 \\
\hline \multicolumn{13}{|l|}{ Hour (UT) } \\
\hline 0.5 & & 95.1 & & & & & 208 & & & & & \\
\hline 1.5 & & & & & & & 123 & 87.7 & & & & \\
\hline 2.5 & & 131 & & & & & & 116 & & & & \\
\hline 3.5 & & & & & & & & 71.0 & 142 & & & \\
\hline 4.5 & & & & & 132 & & 147 & & 136 & & 136 & \\
\hline 5.5 & & & 96.4 & 61.1 & 95.4 & & 75.3 & & 99.1 & & 105 & \\
\hline 6.5 & & 58.7 & 70.1 & & & & 97.8 & & 82.4 & & 104 & \\
\hline 7.5 & & & & & & & 113 & 55.3 & 64.3 & & 78.0 & \\
\hline 8.5 & & & & & & & 105 & 52.5 & 64.4 & & 48.4 & \\
\hline 9.5 & & & 50.9 & & & & 80.7 & & 72.4 & & & \\
\hline 10.5 & & & & & & & 93.1 & 61.5 & 58.7 & & & \\
\hline 11.5 & & & & & & & & 78.3 & 61.9 & & & \\
\hline \multicolumn{13}{|l|}{12.5} \\
\hline 13.5 & & & & & & & 53.8 & & 41.5 & & & \\
\hline \multicolumn{13}{|l|}{14.5} \\
\hline \multicolumn{13}{|l|}{15.5} \\
\hline \multicolumn{13}{|l|}{16.5} \\
\hline \multicolumn{13}{|l|}{17.5} \\
\hline \multicolumn{13}{|l|}{18.5} \\
\hline \multicolumn{13}{|l|}{19.5} \\
\hline 20.5 & & 111 & & & & & 47.5 & & & & & \\
\hline 21.5 & & 155 & & & & & 58.1 & & & & & 79.2 \\
\hline 22.5 & & 160 & & & & & 85.4 & & & & 171 & \\
\hline 23.5 & & & & & & & 190 & & & & & \\
\hline
\end{tabular}


Table A3. Median Electron density at $90 \mathrm{~km}$ for $1 \mathrm{~dB}$ absorption

\begin{tabular}{|c|c|c|c|c|c|c|c|c|c|c|c|c|}
\hline Month & 0.5 & 1.5 & 2.5 & 3.5 & 4.5 & 5.5 & 6.5 & 7.5 & 8.5 & 9.5 & 10.5 & 11.5 \\
\hline \multicolumn{13}{|c|}{ Hour (UT) } \\
\hline 0.5 & & 40.6 & & & & & 41.1 & & & & & \\
\hline 1.5 & & & & & & & 44.4 & 39.2 & & & & \\
\hline 2.5 & & 61.7 & & & & & & 72.5 & & & & \\
\hline 3.5 & & & & & & & & 51.4 & 85.5 & & & \\
\hline 4.5 & & & & & 78.4 & & 108 & & 82.1 & & 57.6 & \\
\hline 5.5 & & & 48.3 & 41.2 & 84.8 & & 42.0 & & 71.5 & & 79.9 & \\
\hline 6.5 & & 53.7 & 58.8 & & & & 61.4 & & 74.7 & & 71.0 & \\
\hline 7.5 & & & & & & & 78.6 & 61.2 & 60.3 & & 56.9 & \\
\hline 8.5 & & & & & & & 68.2 & 63.3 & 52.3 & & 37.9 & \\
\hline 9.5 & & & 48.4 & & & & 49.2 & & 48.6 & & & \\
\hline 10.5 & & & & & & & 53.4 & 57.7 & 50.0 & & & \\
\hline 11.5 & & & & & & & & 57.9 & 51.4 & & & \\
\hline \multicolumn{13}{|l|}{12.5} \\
\hline 13.5 & & & & & & & 30.9 & & 32.8 & & & \\
\hline \multicolumn{13}{|l|}{14.5} \\
\hline \multicolumn{13}{|l|}{15.5} \\
\hline \multicolumn{13}{|l|}{16.5} \\
\hline \multicolumn{13}{|l|}{17.5} \\
\hline \multicolumn{13}{|l|}{18.5} \\
\hline \multicolumn{13}{|l|}{19.5} \\
\hline 20.5 & & 49.5 & & & & & 21.1 & & & & & \\
\hline 21.5 & & 87.6 & & & & & 30.7 & & & & & 34.0 \\
\hline 22.5 & & 86.4 & & & & & 39.2 & & & & 70.3 & \\
\hline 23.5 & & & & & & & 46.9 & & & & & \\
\hline
\end{tabular}

Table A4. Median Electron density at $85 \mathrm{~km}$ for $1 \mathrm{~dB}$ absorption

\begin{tabular}{|c|c|c|c|c|c|c|c|c|c|c|c|c|}
\hline Month & 0.5 & 1.5 & 2.5 & 3.5 & 4.5 & 5.5 & 6.5 & 7.5 & 8.5 & 9.5 & 10.5 & 11.5 \\
\hline \multicolumn{13}{|l|}{ Hour (UT) } \\
\hline 0.5 & & 0 & & & & & 4.77 & & & & & \\
\hline 1.5 & & & & & & & 6.40 & 7.04 & & & & \\
\hline 2.5 & & 16.8 & & & & & & 8.87 & & & & \\
\hline 3.5 & & & & & & & & 13.3 & 26.0 & & & \\
\hline 4.5 & & & & & 27.7 & & 22.1 & & 28.9 & & 18.0 & \\
\hline 5.5 & & & 26.1 & 18.1 & 34.6 & & 9.52 & & 21.7 & & 41.2 & \\
\hline 6.5 & & 35.3 & 33.6 & & & & 14.2 & & 24.1 & & 34.4 & \\
\hline 7.5 & & & & & & & 21.3 & 7.31 & 20.2 & & 33.3 & \\
\hline 8.5 & & & & & & & 21.9 & 27.7 & 24.8 & & 23.6 & \\
\hline 9.5 & & & 28.7 & & & & 12.0 & & 22.7 & & & \\
\hline 10.5 & & & & & & & 10.7 & 23.3 & 18.5 & & & \\
\hline 11.5 & & & & & & & & 18.1 & 20.0 & & & \\
\hline \multicolumn{13}{|l|}{12.5} \\
\hline 13.5 & & & & & & & 0 & & 11.8 & & & \\
\hline \multicolumn{13}{|l|}{14.5} \\
\hline \multicolumn{13}{|l|}{15.5} \\
\hline \multicolumn{13}{|l|}{16.5} \\
\hline \multicolumn{13}{|l|}{17.5} \\
\hline \multicolumn{13}{|l|}{18.5} \\
\hline \multicolumn{13}{|l|}{19.5} \\
\hline 20.5 & & 25.6 & & & & & 0 & & & & & \\
\hline 21.5 & & 27.3 & & & & & 0 & & & & & 5.77 \\
\hline 22.5 & & 29.5 & & & & & 0 & & & & 13.9 & \\
\hline 23.5 & & & & & & & 7.94 & & & & & \\
\hline
\end{tabular}


Table A5. Median Electron density at $80 \mathrm{~km}$ for $1 \mathrm{~dB}$ absorption

\begin{tabular}{|c|c|c|c|c|c|c|c|c|c|c|c|c|}
\hline Month & 0.5 & 1.5 & 2.5 & 3.5 & 4.5 & 5.5 & 6.5 & 7.5 & 8.5 & 9.5 & 10.5 & 11.5 \\
\hline \multicolumn{13}{|c|}{ Hour (UT) } \\
\hline 0.5 & & 0 & & & & & 0 & & & & & \\
\hline 1.5 & & & & & & & 0 & 0 & & & & \\
\hline 2.5 & & 0 & & & & & & 0 & & & & \\
\hline 3.5 & & & & & & & & 0 & 5.22 & & & \\
\hline 4.5 & & & & & 7.81 & & 2.55 & & 6.84 & & 4.01 & \\
\hline 5.5 & & & 10.5 & 3.99 & 8.36 & & 0 & & 0 & & 10.5 & \\
\hline 6.5 & & 12.4 & 9.77 & & & & 0 & & 9.62 & & 8.77 & \\
\hline 7.5 & & & & & & & 0 & 0 & 7.54 & & 11.9 & \\
\hline 8.5 & & & & & & & 4.20 & 8.03 & 9.33 & & 9.09 & \\
\hline 9.5 & & & 10.9 & & & & 0 & & 0 & & & \\
\hline 10.5 & & & & & & & 0 & 7.91 & 0 & & & \\
\hline 11.5 & & & & & & & & 0 & 0 & & & \\
\hline 12.5 & & & & & & & & & & & & \\
\hline 13.5 & & & & & & & 0 & & 0 & & & \\
\hline \multicolumn{13}{|l|}{14.5} \\
\hline \multicolumn{13}{|l|}{15.5} \\
\hline \multicolumn{13}{|l|}{16.5} \\
\hline \multicolumn{13}{|l|}{17.5} \\
\hline \multicolumn{13}{|l|}{18.5} \\
\hline \multicolumn{13}{|l|}{19.5} \\
\hline 20.5 & & 9.71 & & & & & 0 & & & & & \\
\hline 21.5 & & 7.34 & & & & & 0 & & & & & 0 \\
\hline 22.5 & & 9.07 & & & & & 0 & & & & 0 & \\
\hline 23.5 & & & & & & & 0 & & & & & \\
\hline
\end{tabular}

